\title{
A GESTÃo DO CONHECIMENTO E O PROJETO DE
EDIFICAÇÕES
}

\author{
Maria Vitória M.F.P. SILVA \\ Engenheira Civil, Mestra pelo Programa de Pós- \\ graduação em Construção Civil da Universidade Federal \\ de São Carlos.
}

\section{Celso Carlos NOVAES}

Engenheiro Civil, Doutor em Engenharia de Construção Civil e Urbana pela Escola Politécnica da Universidade de São Paulo, professor-orientador no Programa de Pós-Graduação em Construção Civil da UFSCar.

\section{RESUMO}

O presente artigo baseia-se numa pesquisa de mestrado sobre coordenação de projetos e gestão do conhecimento. Traça um paralelo entre a atual visão das empresas de engenharia focada na gestão do conhecimento e a importância do conhecimento dos projetos de edificações, sendo este seu principal insumo e produto final.

Para comprovar e exemplificar a discussão teórica é apresentado um estudo de caso realizado numa construtora e incorporadora nacional de grande porte. É apresentado um histórico da introdução desse conceito na cultura e na estratégia organizacional da empresa, cujo objetivo final é o desenvolvimento de projetos com melhores níveis de qualidade e de construtibilidade, que terão impacto no desempenho de suas edificações.

Palavras-chave: projeto de edificações, gestão do conhecimento, sistemas de informação.

\section{ABSTRACT}

The present paper compares the current vision of the engineering companies focused in the knowledge management with the knowledge importance in the building design, being its main input and final product.

To prove and to exemplify the theoretical discussion it is presented a case study which was accomplished in one real estate development company. The introduction of the concepts in the culture and in the organizational strategy of the company, whose final aim is the development of designs with better level of quality and constructability, will be demonstrated in their buildings performance.

This work bases on a master's degree research about the coordination of building designs and knowledge management.

Keywords: building design, Knowledge management, information systems. 


\section{INTRODUÇÃO}

A chamada "era do conhecimento" se diferencia da era industrial através da sua nova visão, na qual o conhecimento e a informação são considerados recursos intangíveis essenciais às modernas organizações. Nas empresas líderes de mercado, o conhecimento passa a ser o principal foco do negócio. Assim, o processo de produção não se restringe apenas à transformação de recursos físicos em produtos tangíveis, mas, também, à conversão do conhecimento em ativos intangíveis.

“É importante destacar uma das maiores características associadas ao conhecimento que é o fato de ele ser altamente reutilizável, isto é, quanto mais utilizado e difundido maior o seu valor, e ao contrário dos demais recursos materiais, o efeito depreciação funciona ao contrário, pois a depreciação ocorre exatamente quando o conhecimento não é utilizado" (SANTIAGO JÚNIOR, 2002).

Nas empresas do setor de construção civil, "os profissionais de projeto, com base nos seus conhecimentos especializados, vendem muito mais do que um simples produto formado por representações gráficas, especificações técnicas, etc. Nas soluções projetuais estão implícitos conhecimentos e conceitos, que resultaram na concepção dos ambientes, na composição das estruturas e na instalação dos diversos sistemas, elaborados para aquela edificação" SILVA (2005).

Em face da complexidade dos projetos de edificações e para competir, vantajosamente, em uma nova conjuntura econômica de dimensões globais, com exigências cada vez mais crescentes, as empresas de ponta serão impelidas, mais cedo ou mais tarde, a implantar a gestão do conhecimento e a desenvolver as competências de seus diferentes colaboradores.

\section{GESTÃO DO CONHECIMENTO}

Na última década do século passado surgiram dois conceitos que influenciaram as atividades econômicas na sua organização e implementação de métodos de trabalho. A reengenharia e a gestão do conhecimento se destacaram e continuam sendo cada vez mais utilizadas. Segundo o Instituto Avançado de Desenvolvimento Intelectual (IADI), o mundo empresarial foi influenciado pela chamada "era do conhecimento".

A gestão do conhecimento está sendo cada vez mais valorizada, já que o principal recurso estratégico de uma empresa é o seu próprio conhecimento. A sociedade atual está produzindo uma grande quantidade de novos conhecimentos e tecnologias, frutos do crescente desenvolvimento científico e de um maior intercâmbio entre os países (globalização). Dessa forma, a informação eficaz e precisa e o conhecimento assumem um papel de destaque no desenvolvimento e sustentação das organizações.

A gestão do conhecimento não é apenas um modismo, mas sim um modo fundamentalmente novo de se olhar para a organização. Apesar de ainda não ser parte integrante do planejamento estratégico e não estar integrada às práticas de recursos humanos, tem sido, cada vez mais, objeto de pesquisa de diversos especialistas. De acordo com a Fundação Getúlio Vargas (FGV) “não há vantagem competitiva sustentável senão através do que a empresa sabe, como consegue utilizar o que sabe e a rapidez com que aprende algo novo" SALIM (2004). 
Portanto, a gestão do conhecimento torna-se um grande trunfo para as empresas atuais.

O quadro 1 apresenta as principais diferenças de paradigmas entre as empresas da era industrial e da nova era do conhecimento.

\begin{tabular}{|c|c|c|}
\hline ITEM & $\begin{array}{l}\text { PARADIGMA DA ERA } \\
\text { INDUSTRIAL }\end{array}$ & $\begin{array}{l}\text { PARADIGMA DA ERA DO } \\
\text { CONHECIMENTO }\end{array}$ \\
\hline Pessoas & $\begin{array}{l}\text { Geradores de custos ou } \\
\text { recursos }\end{array}$ & Geradores de receita \\
\hline Fonte de poder dos gerentes & $\begin{array}{l}\text { Nível hierárquico na } \\
\text { organização }\end{array}$ & Nível de conhecimento \\
\hline Luta de poder & Operários versus Capitalistas & $\begin{array}{l}\text { Trabalhadores do } \\
\text { conhecimento versus gerentes }\end{array}$ \\
\hline $\begin{array}{l}\text { Principal responsabilidade da } \\
\text { gerência }\end{array}$ & $\begin{array}{l}\text { Supervisionar os } \\
\text { subordinados }\end{array}$ & Apoiar os colegas \\
\hline Informação & Instrumento de controle & $\begin{array}{l}\text { Ferramenta para } \\
\text { comunicação; recurso }\end{array}$ \\
\hline Produção & $\begin{array}{l}\text { Operários processando } \\
\text { recursos físicos para criar } \\
\text { produtos tangíveis }\end{array}$ & $\begin{array}{l}\text { Trabalhadores do } \\
\text { conhecimento convertendo } \\
\text { conhecimento em estruturas } \\
\text { intangíveis }\end{array}$ \\
\hline Fluxo de informação & $\begin{array}{l}\text { Através da hierarquia } \\
\text { organizacional }\end{array}$ & Através de redes colegiadas \\
\hline Gargalos na produção & $\begin{array}{l}\text { Capital financeiro e } \\
\text { habilidades humanas }\end{array}$ & Tempo e conhecimento \\
\hline Fluxo de produção & $\begin{array}{l}\text { Direcionado pelas máquinas; } \\
\text { seqüencial }\end{array}$ & $\begin{array}{l}\text { Direcionado pelas idéias, } \\
\text { caótico }\end{array}$ \\
\hline Efeito do tamanho & $\begin{array}{l}\text { Economia de escala no } \\
\text { processo de produção }\end{array}$ & Economia de escopo das redes \\
\hline Relação com os clientes & $\begin{array}{l}\text { Unidirecional através dos } \\
\text { mercados }\end{array}$ & $\begin{array}{l}\text { Interativa através de redes } \\
\text { pessoais }\end{array}$ \\
\hline Conhecimento & $\begin{array}{l}\text { Uma ferramenta ou recurso } \\
\text { entre outros }\end{array}$ & O foco do negócio \\
\hline Propósito do aprendizado & $\begin{array}{l}\text { Aplicação de novas } \\
\text { ferramentas }\end{array}$ & Criação de novos ativos \\
\hline Valores de mercado (de ações) & $\begin{array}{l}\text { Devidos, em grande parte, aos } \\
\text { ativos tangíveis }\end{array}$ & $\begin{array}{l}\text { Devido, em grande parte, aos } \\
\text { ativos intangíveis }\end{array}$ \\
\hline Economia & $\begin{array}{l}\text { Baseada em retornos } \\
\text { decrescentes }\end{array}$ & $\begin{array}{l}\text { Baseada em retornos } \\
\text { crescentes e decrescentes }\end{array}$ \\
\hline
\end{tabular}

Fonte: SVEIBY apud TERRA (1999)

\section{Quadro 1: Os princípios da organização baseada no conhecimento}

O conceito atual da sociedade da informação ou do conhecimento caracteriza-se pela "intensidade, velocidade e abrangência com as quais as informações se propagam e são utilizadas, assim, como novos conhecimentos são gerados" (KASZKUREWICZ apud PEZZO, 2003). 
"A bibliografia que trata o conhecimento como um objeto é complementada por outra bibliografia, que foca o processo da criação do conhecimento (....) a primeira perspectiva procura abstrair o conhecimento das pessoas que o criam e implementam, a segunda, que foca o conhecimento como processo, envolve os processos individuais e sociais de criatividade, inovação, motivação e comunicação". (SPENDER, 2001)

As empresas de ponta estão criando uma área exclusiva para a gestão do conhecimento. Além de aprimorar o chamado capital intelectual, seu papel é recrutar e desenvolver os talentos que colocarão em prática a estratégia da empresa em todas as suas áreas. Para as empresas modernas gerenciar o fator intelectual e humano é tão importante quanto o recurso físico e financeiro.

Atualmente verifica-se uma tendência em valorizar o capital intelectual na atividade econômica, como nunca ocorreu antes. O capital intelectual apresenta dois componentes: o capital humano e o ativo intelectual.

O capital humano abrange valores, cultura organizacional da empresa, capacidade individual de seus funcionários e colaboradores em combinar conhecimentos e habilidades para inovar e realizar suas tarefas. Engloba o conhecimento tácito e organizacional, incluindo a criatividade, a inovação, experiências, qualificações e know how. O ativo intelectual conhecido como propriedade intelectual da empresa, compreende conhecimento codificado (patentes, marcas, segredos comerciais legalmente protegidos), direitos autorais, programas, processos operacionais, banco de dados, hardware e software. (BITTENCOURT, 2002; TERRA, 1999)

O poder econômico e de produção de uma empresa moderna concentra-se mais em suas capacidades intelectuais e de serviço do que em seus ativos imobilizados. $\mathrm{O}$ valor da maioria dos produtos e serviços depende principalmente de como os fatores intangíveis baseados no conhecimento (projeto de produto, know-how tecnológico, criatividade e inovação, entre outros) podem ser desenvolvidos (QUIN apud NONAKA; TAKEUCHI, 1997).

Os ativos intangíveis agregam valor à maioria dos produtos ou serviços e são baseados em conhecimento. Ao contrário dos ativos tangíveis o valor econômico do conhecimento ou ativo intangível não é facilmente apropriado e mensurado. (SANTIAGO JÚNIOR, 2002)

Nas empresas atuais da era do conhecimento, o patrimônio intelectual é fundamental e mais importante que o financeiro. O capital monetário investido na produção de bens e serviços corteja cada dia mais o capital intelectual, já contabilizado por algumas corporações, e deste dependerá para a sua sobrevivência, em um ambiente altamente competitivo.

\subsection{Tipos de conhecimento}

O conhecimento tem duas formas: explícita e tácita. O conhecimento explícito pode ser transmitido, formalizado e sistematizado, entre os indivíduos e expresso em: palavras, números e desenhos, em forma de dados e manuais. O conhecimento tácito encontra-se no limite entre a percepção e a intuição, é pessoal e difícil de formalizar. Compreende duas dimensões: a técnica freqüentemente relacionada ao 
saber-fazer que engloba a habilidade informal de pessoas ou grupos; e a dimensão cognitiva que traduz a maneira como o homem compreende o mundo, consistindo em ideais, valores e modelos mentais. (NONAKA; TAKEUCHI,1997)

A figura 1 relaciona os conhecimentos organizacional e codificado que constituem o capital intelectual de uma empresa.

\begin{tabular}{|c|c|}
\hline $\begin{array}{l}\text { CONHECIMENTO } \\
\text { ORGANIZACIONAL }\end{array}$ & $\begin{array}{l}\text { CONHECIMENTO } \\
\text { CODIFICADO }\end{array}$ \\
\hline CAPITAL HUMANO & \multirow{3}{*}{$\begin{array}{l}\text { ATIVO INTELECTUAL } \\
\begin{array}{|l|l}\begin{array}{l}\text { Propriedade intelectual } \\
\text { patentes, direitos autorais }\end{array}\end{array}\end{array}$} \\
\hline Conhecimento Sistêmico & \\
\hline Conhecimento Explícito & \\
\hline Conhecimento Tácito & \begin{tabular}{|l|} 
Programas \\
\end{tabular} \\
\hline Conhecimento Escondido & Processos operacionais \\
\hline Conhecimento Relacional & Banco de dados \\
\hline
\end{tabular}

Figura 1: Mapa do conhecimento

A geração do conhecimento organizacional "depende, em grande medida, do contato humano, da intuição, do conhecimento tácito, da cooperação, da explicitação de modelos mentais, da diversidade de opiniões e do pensamento sistêmico" (TERRA, 1999).

Pode-se conceituar e delinear cinco tipos de conhecimento organizacional: sistêmico, explícito, tácito, escondido e relacional, os quais embasam a gestão do conhecimento nas organizações econômicas. As definições desses tipos de conhecimento são as seguintes:

\section{- Sistêmico}

Apóia-se na perspectiva individual e favorece o surgimento de diferentes pontos de vista na organização. Os profissionais em uma determinada organização interpretam de forma distinta um mesmo fenômeno, conferindolhe vários significados relativos, pois cada um possui um grau de conhecimento sistêmico e enxerga a realidade por uma perspectiva própria. (KNOR-CETINA;CZARNIAWSKA-JOERGES apud JOHANNESSEN; OLSEN; OLAISEN, 1999)

\section{- Explícito}

Conhecimento facilmente comunicado e compartilhado. É sistematizado e formalizado, por exemplo, através de especificações de produtos, fórmulas científicas e programas de computador, para poder ser transmitido a diversos profissionais. (NOKADA apud TRISKA, 2001)

\section{- Tácito}

Ponto de partida para a inovação, é altamente pessoal e difícil de formalizar (NOKADA apud TRISKA, 2001). É o conhecimento prático adquirido pelos indivíduos através de suas experiências profissionais, de acordo com os seus valores pessoais. 


\section{- Escondido}

São as premissas, pré-requisitos e motivos que influenciam o pensar e agir como uma espécie de paradigma. Ele organiza o desenvolvimento de modelos mentais e a escolha de variáveis. Este conhecimento pode ser dividido em duas partes: disposição para pensar e disposição para agir. (JOHANNESSEN; OLSEN; OLAISEN, 1999)

\section{- Relacional}

Envolve a capacidade de estabelecer relacionamentos com grupos especializados para utilização de seus conhecimentos (LUNDVALL apud JOHANNESSEN OLSEN; OLAISEN, 1999). Está ligado à "inteligência interpessoal" dos profissionais, necessária para estabelecer a sinergia dos membros de uma equipe. Este tipo de conhecimento é o mais importante para a atividade de coordenação de projetos.

O quadro 2, a seguir, esquematiza os diferentes tipos de conhecimento organizacional.

\begin{tabular}{|c|c|c|c|c|}
\hline $\begin{array}{c}\text { Conhecimento } \\
\text { Tipos }\end{array}$ & $\begin{array}{c}\text { Aprendido } \\
\text { Por }\end{array}$ & $\begin{array}{c}\text { O que é } \\
\text { Aprendido }\end{array}$ & $\begin{array}{c}\text { Como é } \\
\text { Transferido }\end{array}$ & Meio \\
\hline Sistêmico & $\begin{array}{l}\text { Estudo de } \\
\text { padrões }\end{array}$ & $\begin{array}{l}\text { Know why } \\
\text { Novas } \\
\text { maneiras de } \\
\text { pensar }\end{array}$ & $\begin{array}{c}\text { Simulação } \\
\text { computadorizad } \\
\text { a Planejamento } \\
\text { de cenário }\end{array}$ & $\begin{array}{l}\text { Ferramentas } \\
\text { sistêmicas }\end{array}$ \\
\hline Explícito & $\begin{array}{l}\text { Ouvindo } \\
\text { Lendo }\end{array}$ & Know what & Comunicação & $\begin{array}{l}\text { Mídia impressa } \\
\text { Mídia digital }\end{array}$ \\
\hline Tácito & $\begin{array}{c}\text { Usando } \\
\text { Fazendo } \\
\text { Experimentando }\end{array}$ & Know how & $\begin{array}{l}\text { Brainstorming } \\
\text { camps }\end{array}$ & $\begin{array}{c}\text { Experiência } \\
\text { prática } \\
\text { Aprendizagem } \\
\text { nos } \\
\text { relacionamentos }\end{array}$ \\
\hline Escondido & Socialização & $\begin{array}{l}\text { Conhecer } \\
\text { como nós } \\
\text { conhecemos }\end{array}$ & $\begin{array}{l}\text { Grupos de } \\
\text { solução }\end{array}$ & $\begin{array}{l}\text { Questionando } \\
\text { suposições } \\
\text { implícitas } \\
\text { Modelos mentais }\end{array}$ \\
\hline Relacional & Interação & Know who & $\begin{array}{c}\text { Parcerias } \\
\text { Equipes }\end{array}$ & Ajustes sociais \\
\hline
\end{tabular}

Fonte: adaptado de JOHANNESSEN; OLSEN; OLAISEN (1999)

\section{Quadro 2: Tipos de conhecimento organizacional}

Conforme SANTIAGO JÚNIOR (2002) observou, a gestão do conhecimento não se limita à criação de novos conhecimentos, mas também à organização daqueles já existentes, mas não utilizados de forma adequada. A empresa possui a maior parte do conhecimento necessário para o desenvolvimento de novos projetos e para se manter competitiva. Portanto, as empresas devem resgatar e utilizar o seu conhecimento adquirido em projetos já realizados. 


\subsection{Aplicação do conhecimento}

“A gestão do conhecimento é uma abordagem relativamente nova na administração de empresas e trata de métodos e meios para assegurar que a empresa adquira, mantenha e administre o conhecimento de que necessita para atuar" (SILVA; SOUZA, 2003). "É o processo sistemático de identificação, criação, renovação e aplicação dos conceitos que são estratégicos na vida de uma organização" (PACHECO apud YAMUCHI, 2003).

Os mecanismos de suporte à gestão do conhecimento, de acordo com TERRA (1999), compreendem:

> Sistemas de informação: reflete o grau de importância que a empresa confere ao acúmulo e compartilhamento de informações e do conhecimento.

> Políticas para a administração de recursos humanos: é através destas que "as empresas expressam, com maior constância, o tipo de pessoas, habilidades e atitudes que são desejadas".

> Sistemas de mensuração de resultado: "indicam aos funcionários quais são alguns dos principais pontos de atenção da empresa".

A figura 2 esquematiza o processo do conhecimento dentro de uma organização.

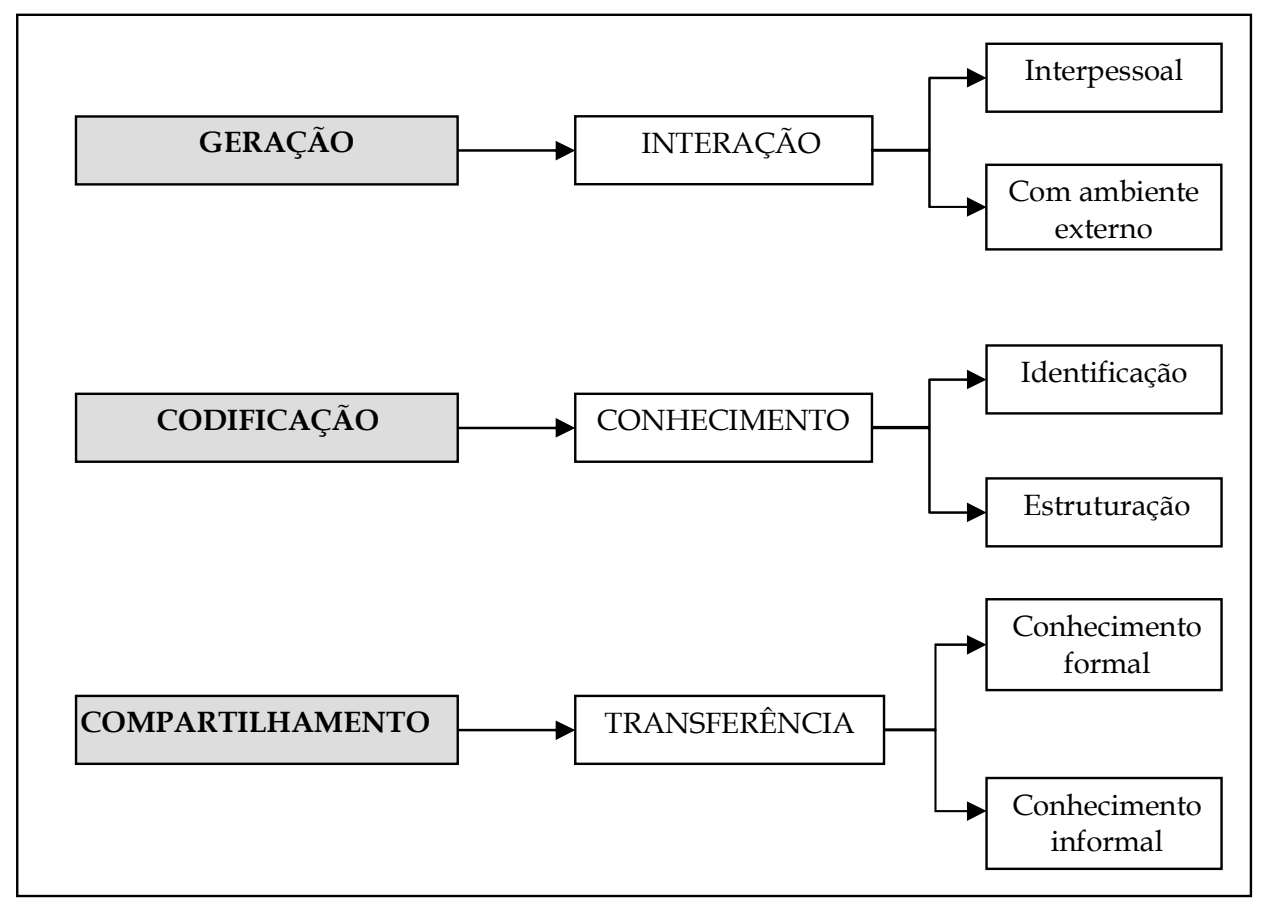

Fonte: baseado em DAVENPORT; PRUSK apud MUSSI; ANGELONI (2000)

Figura 2 - Processo de gestão do conhecimento

A meta da gestão do conhecimento é a aplicação adequada do conhecimento gerado, estruturado e transferido, visando um determinado objetivo. De acordo com DAVENPORT; PRUSK apud MUSSI; ANGELONI, 2000, o processo de gestão do conhecimento compreende a geração, codificação e o compartilhamento do conhecimento: 


\section{- Geração}

Refere-se a todas as formas de criação do conhecimento, seja a partir da interação com o ambiente externo ou até mesmo por meio da interação interpessoal.

\section{- Codificação}

Tem como objetivo identificar e estruturar os conhecimentos.

\section{- Compartilhamento}

Refere-se à transferência do conhecimento formal ou informal.

As organizações ao avaliarem novos investimentos e projetos devem priorizar o crescimento do estoque de conhecimento. Este deve ser alinhado com os objetivos estratégicos, usando indicadores próprios para mensurar e avaliar os esforços na criação de capital intelectual. As empresas cujas práticas gerenciais estão relacionadas à gestão do conhecimento (estímulo ao aprendizado, à criatividade e à inovação) apresentam melhores desempenhos de acordo com pesquisas realizadas junto a executivos de grandes e médias empresas. (TERRA, 1999)

O profissional inserido nestas práticas gerenciais é considerado como um trabalhador do conhecimento que demonstra na sua performance quatro aspectos de conhecimento individual: o cognitivo, o científico, o criativo e o tácito.

O quadro 3 descreve as características básicas do conhecimento individual, de acordo com FRANCO (2001).

\begin{tabular}{|c|l|}
\hline Características & \multicolumn{1}{|c|}{ Descrição } \\
\hline $\begin{array}{c}\text { Conhecimento Cognitivo } \\
\text { know-what }\end{array}$ & $\begin{array}{l}\text { Conhecimentos codificados adquiridos através das prescrições: } \\
\text { política da empresa, procedimentos adotados. }\end{array}$ \\
\hline $\begin{array}{c}\text { Habilidades Avançadas } \\
\text { know-how }\end{array}$ & $\begin{array}{l}\text { Construídas a partir das experiências e aparecem nas rotinas das } \\
\text { atividades diárias. } \\
\text { O trabalhador experiente tem muito mais habilidade para } \\
\text { desempenhar uma tarefa do que o aprendiz. }\end{array}$ \\
\hline $\begin{array}{c}\text { Visão Sistêmica } \\
\text { know-why }\end{array}$ & $\begin{array}{l}\text { Conhecimentos científicos (técnico e tecnológico), conhecimentos } \\
\text { mais elaborados que procuram saber o por quê dos } \\
\text { acontecimentos. }\end{array}$ \\
\hline $\begin{array}{c}\text { Criatividade Automotivadora } \\
\text { Care-why }\end{array}$ & $\begin{array}{l}\text { O por quê dos envolvimentos. } \\
\text { Introduz modificações na cultura organizacional. }\end{array}$ \\
\hline
\end{tabular}

Fonte: Baseado em FRANCO (2001)

\section{Quadro 3: Características do conhecimento individual}

A principal vantagem competitiva das empresas baseia-se no capital humano ou ainda no conhecimento tácito que seus colaboradores possuem, sendo difícil de ser imitado e "reengenheirado", de acordo com TERRA (1999).

A gestão do conhecimento está ligada à capacidade destas em utilizar e combinar os vários tipos de conhecimento organizacional para desenvolverem competências específicas e capacidades inovadoras, que se concretizam em novos produtos, processos, sistemas gerenciais e liderança de mercado (NONAKA; TAKEUCHI apud TERRA, 1999). 


\subsection{A gestão do conhecimento e as competências}

A competência extrapola o conhecimento, ela precisa das habilidades necessárias e das atitudes adequadas para desempenhar um determinado trabalho. Desenvolver ou dinamizar competências é interagir e potencializar conhecimentos e talentos para agregar valores.

Conforme observou TERRA (1999), o capital humano é a "mola propulsora" da geração de conhecimento nas empresas, formado por valores e normas individuais e organizacionais, competências, habilidades e atitudes de cada profissional. Portanto, necessita-se fomentar valores apropriados à inovação e ao compartilhamento do conhecimento e estimular o estabelecimento de contatos pessoais, a análise de diferentes perspectivas, a abertura para efetiva comunicação e o desenvolvimento de competências.

A competência é "um saber agir responsável e reconhecido que implica mobilizar, integrar, transferir conhecimentos, recursos, habilidades, que agreguem valor econômico à organização e valor social ao indivíduo" (FLEURY; FLEURY apud OLIVEIRA JUNIOR, 2001).

As noções de competência surgiram nos últimos anos como uma nova forma de repensar as interações entre os profissionais com seus conhecimentos e capacidades e as organizações com suas demandas nos processos de trabalho (RUAS, 2001).

Prevalecem como elementos de referência no estudo sobre competência, independente da abordagem e da classificação, os três grandes eixos clássicos: conhecimento (saber); habilidades (saber-fazer) e atitudes (saber-ser), conforme representado na figura 3:

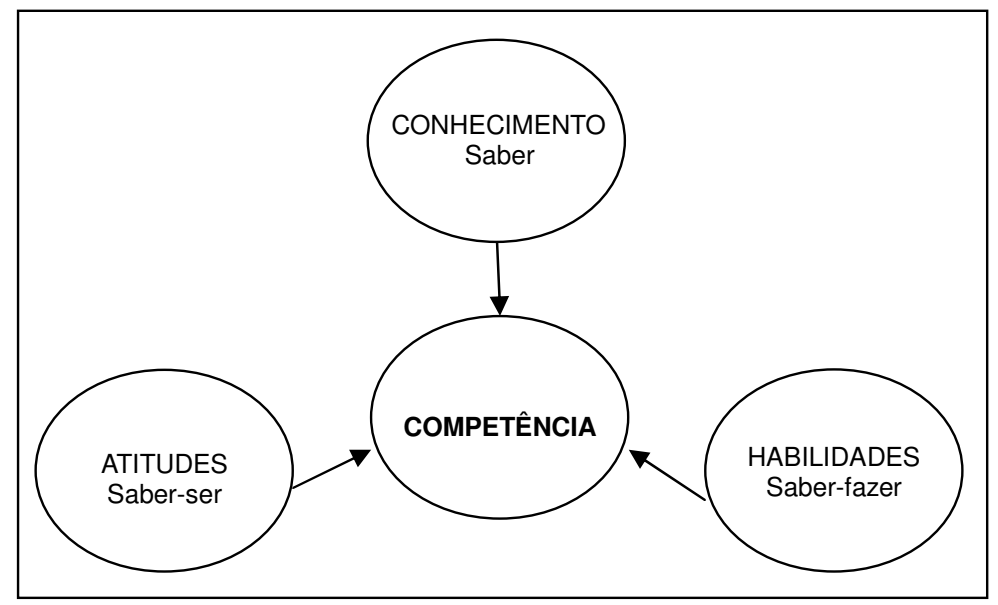

Fonte: SILVA (2005)

Figura 3: Os eixos clássicos da competência

Então, o que define uma pessoa ou empresa competente é aquela que tem o conhecimento, os recursos necessários, os meios e as técnicas (habilidades) e age numa determinada situação da forma mais acertada, ou seja, tem a atitude mais correta e escolhe a melhor decisão.

O mapeamento das competências facilita a localização dos detentores de conhecimento, agilizando sua disseminação e a formação de equipes para novos 
projetos. O mapa do conhecimento revela pontos fortes a serem explorados e as lacunas a serem preenchidas. (SANTIAGO JÚNIOR, 2002)

O quadro 4 apresenta um mapa de competências para empresas do setor de construção civil.

\begin{tabular}{|c|c|c|c|}
\hline $\begin{array}{c}\text { Competências } \\
\text { Organizacionais }\end{array}$ & $\begin{array}{l}\text { Processo } \\
\text { Gerencial }\end{array}$ & $\begin{array}{l}\text { Competências } \\
\text { Gerenciais }\end{array}$ & Princípios \\
\hline & & $\begin{array}{l}\text { Conhecimento de } \\
\text { Tecnologia }\end{array}$ & \\
\hline Solução da Engenharia & $\begin{array}{c}\text { Avaliar Impacto no } \\
\text { Prazo }\end{array}$ & $\begin{array}{l}\text { Capacidade de } \\
\text { Negociação }\end{array}$ & Liderança \\
\hline $\begin{array}{l}\text { Flexibilidade no } \\
\text { Atendimento }\end{array}$ & Estimativas de Custos & Mobilizar Parceiros & Ética \\
\hline $\begin{array}{l}\text { Lidar com a } \\
\text { Complexidade }\end{array}$ & $\begin{array}{l}\text { Buscar Soluções de } \\
\text { Projeto }\end{array}$ & $\begin{array}{c}\text { Captar Requisitos do } \\
\text { Cliente }\end{array}$ & Empreendedorismo \\
\hline \multirow[t]{5}{*}{ Inovação Gerencial } & Controle de Custos & Condução de Reuniões & Visão Estratégica \\
\hline & $\begin{array}{l}\text { Sistema de Gestão da } \\
\text { Produção }\end{array}$ & Capacidade de Crítica & Comunicação \\
\hline & $\begin{array}{c}\text { Concepção Sistema de } \\
\text { Produção }\end{array}$ & $\begin{array}{c}\text { Clima Organizacional } \\
\text { Positivo }\end{array}$ & Trabalho em equipe \\
\hline & & $\begin{array}{l}\text { Gerenciamento do } \\
\text { Tempo }\end{array}$ & \\
\hline & & $\begin{array}{c}\text { Conceitos e } \\
\text { Ferramentas de Gestão }\end{array}$ & \\
\hline
\end{tabular}

Fonte: NEVES; FORMOSO (2003)

\section{Quadro 4 - Mapa de competências}

As dimensões da competência dentro de uma organização são apresentadas no quadro 5:

\begin{tabular}{|c|l|l|}
\hline $\begin{array}{c}\text { Dimensões } \\
\text { da competência }\end{array}$ & \multicolumn{1}{|c|}{ Noções } & \multicolumn{1}{c|}{ Abrangência } \\
\hline Essenciais & $\begin{array}{l}\text { Diferenciam a empresa perante } \\
\text { concorrentes e clientes. Constituem } \\
\text { a razão de sua sobrevivência. }\end{array}$ & $\begin{array}{l}\text { Devem estar presentes em todas as } \\
\text { áreas, grupos e pessoas da } \\
\text { organização, embora em níveis } \\
\text { diferenciados. }\end{array}$ \\
\hline Funcionais & $\begin{array}{l}\text { Específicas a cada uma das áreas } \\
\text { vitais da empresa (ex.: vender, } \\
\text { produzir, conceber). }\end{array}$ & $\begin{array}{l}\text { Estão presentes entre os grupos e } \\
\text { pessoas de cada área. }\end{array}$ \\
\hline Individuais & $\begin{array}{l}\text { Compreendem as competências } \\
\text { gerenciais. }\end{array}$ & $\begin{array}{l}\text { Podem exercer importante } \\
\text { influência no desenvolvimento das } \\
\text { competências dos grupos ou até } \\
\text { mesmo da organização. }\end{array}$ \\
\hline
\end{tabular}

Fonte: adaptado de RUAS (2001)

\section{Quadro 5: Dimensões organizacionais da competência}

As competências essenciais de uma organização são o conjunto de recursos intangíveis específicos da empresa, difíceis de serem imitados ou copiados pelos 
seus concorrentes. "Quanto mais amplo o escopo do conhecimento integrado em uma competência, maior a dificuldade de imitação se torna" (GRANT apud OLIVEIRA JUNIOR, 2001).

Segundo PRAHALAD; HAMEL apud OLIVEIRA JUNIOR (2001), as competências essenciais estão associadas à aprendizagem coletiva dentro da organização, especialmente no que se refere a como coordenar diversas habilidades de produção e integrar múltiplos streams (fluxos) de tecnologias.

Em uma empresa de projetos ou construtora, a gestão do conhecimento deve alavancar o desenvolvimento das competências das diferentes especialidades de projeto envolvidas na realização de um empreendimento. Esse desenvolvimento é o resultado do alinhamento e da integração do conhecimento de diversos colaboradores, que agrega valor ao produto a edificar, gerando assim, vantagem competitiva para a empresa.

\section{GESTÃO DO CONHECIMENTO APLICADA AOS PROJETOS DE EDIFICAÇÕES}

A gestão do conhecimento nos projetos de edificações deve integrar o conhecimento especializado e desenvolver as competências dos diversos profissionais envolvidos. Assim, as empresas e profissionais devem registrar, disseminar e utilizar o conhecimento adquirido nos vários projetos realizados.

Em um empreendimento imobiliário, a etapa de projeto envolve um grande volume de conhecimento e é nesta que se definem não só características do produto a ser edificado, mas também do processo produtivo. Portanto, gerir conhecimento é inerente às atividades que envolvem o processo de projeto. A sistematização dessa gestão através de ações e práticas bem definidas, contribui de forma significativa para o desenvolvimento dos projetos de edificações.

A gestão do conhecimento, especialmente para as empresas de projeto é uma necessidade recente, de acordo com SILVA; SOUZA (2003), pois sem ela as empresas sofrem as conseqüências dos limites impostos pelas dificuldades em:

$>$ difundir o conhecimento por toda a empresa em níveis compatíveis com as exigências dos clientes;

$>$ acompanhar a evolução do conhecimento com a velocidade necessária para competir;

$>$ organizar e reter na empresa o conhecimento acumulado ao longo de sua existência.

SOUZA E SILVA; HEINECK, 2001 caracterizam “a equipe de projetos de edificações como uma equipe de gestão do conhecimento", pois essas equipes "apresentam um grande potencial em constituírem-se em um centro de informação e conhecimento devido às exigências de intensiva troca e análise de informação imposta pela própria natureza do produto a ser projetado."

Em empreendimentos imobiliários pode-se destacar a equipe de projeto de edificações, que se constitui não somente dos profissionais de projeto mas de outros agentes envolvidos. O quadro 6 apresenta as características ideais de uma 
equipe de projeto e os resultados a serem obtidos durante a preparação e o desenvolvimento dessa equipe.

\begin{tabular}{|l|l|}
\hline \multicolumn{1}{|c|}{ Características } & \multicolumn{1}{c|}{ Resultados } \\
\hline - linguagem comum & - transparência nas informações \\
- entendimento formal do projeto & - consenso entre pontos de vista divergentes \\
- capacidade de elaborar planejamento e & - preparação da equipe de projeto para a \\
esclarecer problemas relativos ao projeto & necessidade da ocorrência de eventuais riscos \\
- habilidade para contribuir na gestão do & - ampliação da criatividade \\
projeto através de elaboração de relatório de & - inter-relacionamento pessoal harmonioso e \\
necessidades & agradável \\
- reconhecimento das condições de trabalho & - identificação comportamental entre os \\
- entendimento da contribuição de cada & membros e sua fidelidade à equipe \\
especialista para o sucesso do projeto & \\
\hline
\end{tabular}

Fonte: baseado em SOUZA E SILVA; HEINECK (2001)

\section{Quadro 6: Equipe de projeto}

De acordo com SILVA (2005), “a sinergia dos membros de uma equipe de projetos com seus conhecimentos multidisciplinares e competências objetiva alcançar, com a máxima eficiência, as metas pré-determinadas nas diversas fases do processo de projeto. A realização dessas metas constitui-se na principal prioridade da coordenação de projetos e de sua equipe."

A coordenação de projetos de edificações ao formalizar equipes de projeto, através da sistematização, documentação e controle de suas atividades, tem a oportunidade de formar competências. A competência que se espera de uma equipe de projetistas é a competência organizacional e a que se exige de um coordenador de projetos é a competência gerencial. (SILVA, 2005)

A figura 4 é representativa da equipe de gestão do conhecimento para projetos de edificações.

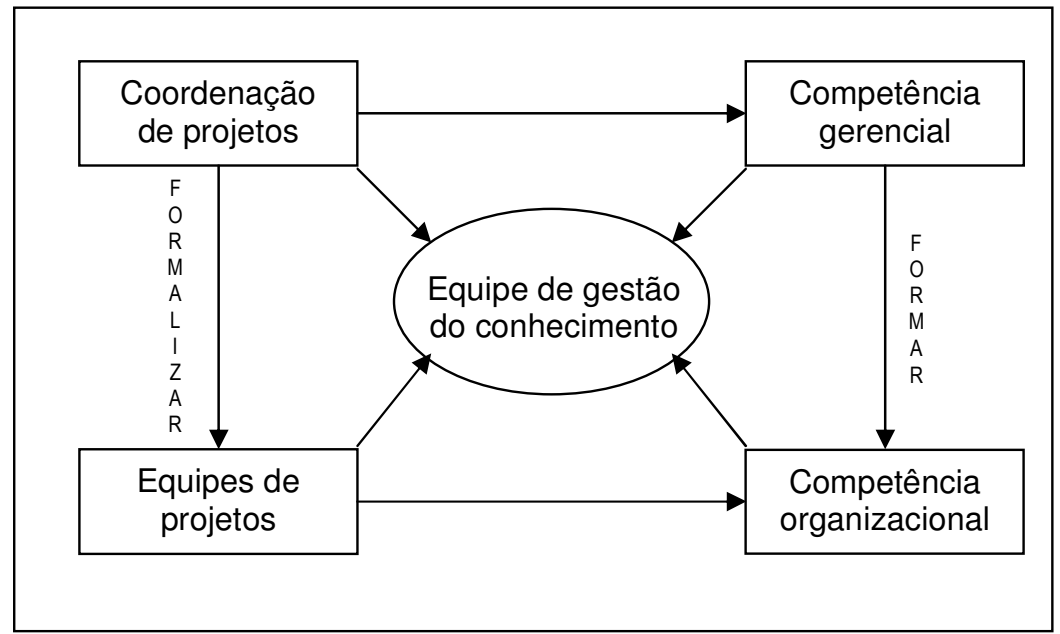

Fonte: SILVA (2005)

Figura 4: Equipe de gestão do conhecimento 
A competência gerencial envolve além da visão estratégica, liderança e habilidade para estabelecer relacionamentos e gerenciar a equipe de projetos, caracterizandose como uma competência tácita, advinda da experiência, capacidade e valores pessoais do coordenador. (SILVA, 2005)

A competência organizacional "é a capacidade de mobilizar, integrar e colocar em ação um conjunto de recursos com a finalidade de atingir o desenvolvimento esperado, de acordo com os objetivos estratégicos da empresa" (RUAS et al apud NEVES; FORMOSO, 2003).

GRANT apud OLIVEIRA JUNIOR (2001) afirma que o "papel primário da organização é a integração do conhecimento mais do que a criação do conhecimento. Os mecanismos de coordenação do conhecimento de especialistas são o caminho para essa integração." O quadro 7 descreve esses caminhos para integrar o conhecimento especializado.

\begin{tabular}{|c|l|}
\hline Mecanismos & \multicolumn{1}{|c|}{ Descrição } \\
\hline Regras e instruções & $\begin{array}{l}\text { Padrões que regulam as interações entre indivíduos. } \\
\text { Proporcionam a conversão de conhecimento tácito em } \\
\text { conhecimento explícito. }\end{array}$ \\
\hline Sequenciamento & $\begin{array}{l}\text { Organiza atividades de produção em uma seqüência de tempo } \\
\text { padronizada, de forma que a contribuição de cada especialista } \\
\text { ocorra independentemente, através de tarefas designadas em } \\
\text { um período de tempo determinado. Meio pelo qual indivíduos } \\
\text { podem integrar seu conhecimento especializado, ao mesmo } \\
\text { tempo em que minimizam comunicação e coordenação. }\end{array}$ \\
\hline Rotinas & $\begin{array}{l}\text { Padrões de comportamento que possuem a habilidade de } \\
\text { suportar padrões de interação complexos entre indivíduos na } \\
\text { ausência de regras e instruções. Ou então, na ausência de } \\
\text { comunicação verbal significativa, assim como variadas } \\
\text { seqüências de interações. }\end{array}$ \\
\hline $\begin{array}{c}\text { Solução de problemas } \\
\text { Tomada de decisão }\end{array}$ & $\begin{array}{l}\text { Equipes que pressupõem formas de integração mais pessoais e } \\
\text { comunicação intensiva, mais adequada a tarefas não usuais, } \\
\text { complexas e importantes. }\end{array}$ \\
\hline
\end{tabular}

Fonte: baseado em GRANT apud OLIVEIRA JUNIOR (2001)

\section{Quadro 7: Mecanismos de integração do conhecimento}

"A atividade de coordenação de projetos num contexto competitivo será a mais propensa a gerir e integrar conhecimentos de diversas especialidades e desenvolver competências. Ela pode ser definida, conceitualmente, como uma coordenação de criação, compartilhada e multidisciplinar. Assim, os diferentes agentes no processo de projeto compartilham os seus conhecimentos e as suas competências, conciliadas e integradas pela diretriz coordenadora, visando, em última instância, a qualidade do produto final." (SILVA, 2005)

Para se obter melhorias na qualidade, redução do prazo de execução dos projetos e "estruturar o conhecimento de forma a torná-lo explícito e de fácil acesso, para ser utilizado nas atividades operacionais ou como instrumento de capacitação, por meio da coordenação e integração das diversas iniciativas e projetos existentes na empresa", SANTIAGO JÚNIOR (2002) apresenta uma metodologia de gestão do 
conhecimento de uma empresa de engenharia voltada para o desenvolvimento de projetos, conforme descrita no quadro 8.

\begin{tabular}{|c|c|c|}
\hline AÇÕES & OBJETIVOS & ATIVIDADES \\
\hline $\begin{array}{l}\text { Levantamento dos } \\
\text { conhecimentos técnicos } \\
\text { para o desenvolvimento } \\
\text { dos projetos da } \\
\text { empresa. }\end{array}$ & $\begin{array}{l}\text { Focar os conhecimentos } \\
\text { a serem adquiridos e ou } \\
\text { desenvolvidos. }\end{array}$ & $\begin{array}{l}\text { Levantar os conhecimentos técnicos necessários e } \\
\text { definir o seu grau de importância. } \\
\text { Associar os conhecimentos técnicos com as } \\
\text { responsabilidades da diretoria técnica e } \\
\text { identificar os que são mais relevantes. } \\
\text { Associar as responsabilidades da diretoria técnica } \\
\text { com as competências técnicas. }\end{array}$ \\
\hline $\begin{array}{l}\text { Definição de um plano } \\
\text { de capacitação técnica } \\
\text { integrado à RH, } \\
\text { considerando as várias } \\
\text { competências técnicas. }\end{array}$ & $\begin{array}{l}\text { Colocar em prática a } \\
\text { "busca" dos } \\
\text { conhecimentos } \\
\text { necessários para o } \\
\text { desenvolvimento dos } \\
\text { projetos. }\end{array}$ & $\begin{array}{l}\text { Analisar criticamente as competências técnicas } \\
\text { identificadas e definir como elas podem ser } \\
\text { adquiridas e/ ou desenvolvidas. } \\
\text { Identificar os meios para a aquisição das } \\
\text { competências necessárias (cursos, workshops, } \\
\text { etc.) e orçar o investimento para o } \\
\text { desenvolvimento do plano de capacitação. } \\
\text { Aprovar o plano de capacitação. }\end{array}$ \\
\hline $\begin{array}{l}\text { Disseminação das } \\
\text { competências técnicas } \\
\text { nas áreas de projeto. }\end{array}$ & $\begin{array}{l}\text { Compartilhar e } \\
\text { disseminar as } \\
\text { competências técnicas } \\
\text { para o desenvolvimento } \\
\text { dos projetos a partir do } \\
\text { mapeamento de } \\
\text { profissionais que } \\
\text { assumirão o papel de } \\
\text { multiplicadores. }\end{array}$ & $\begin{array}{l}\text { Estabelecer diretrizes para a disseminação das } \\
\text { competências junto aos projetos. } \\
\text { Desenvolver procedimentos prescritivos } \\
\text { operacionais sobre as atividades desenvolvidas } \\
\text { na diretoria técnica e definir grau de prioridade } \\
\text { de implantação destes. } \\
\text { Definir o perfil técnico de cada multiplicador sob } \\
\text { o ponto de vista de conhecimento, habilidade e } \\
\text { capacidade gerencial. } \\
\text { Acompanhar e avaliar a disseminação do } \\
\text { conhecimento. }\end{array}$ \\
\hline $\begin{array}{l}\text { Resgate do } \\
\text { conhecimento explícito } \\
\text { da empresa. }\end{array}$ & $\begin{array}{l}\text { Pesquisar o acervo de } \\
\text { conhecimentos } \\
\text { explícitos e experiências } \\
\text { registradas disponíveis } \\
\text { e criar condição que } \\
\text { permita viabilizar sua } \\
\text { utilização para o } \\
\text { desenvolvimento de } \\
\text { projetos. }\end{array}$ & $\begin{array}{l}\text { Localizar áreas de armazenamento do } \\
\text { conhecimento explícito e diagnosticar o quanto } \\
\text { deste conhecimento é utilizado. Identificar o } \\
\text { grau de envolvimento deste sistema de guarda } \\
\text { com as atividades operacionais e estratégicas da } \\
\text { empresa. Identificar a necessidade de remodelar } \\
\text { e/ou incentivar a utilização dos conhecimentos já } \\
\text { explicitados. } \\
\text { Criar centro de conhecimento que permita um } \\
\text { maior envolvimento do acervo técnico com as } \\
\text { atividades desenvolvidas nos projetos. }\end{array}$ \\
\hline $\begin{array}{l}\text { Desenvolvimento de } \\
\text { uma estrutura analítica } \\
\text { do conhecimento } \\
\text { técnico, com base nos } \\
\text { tipos de serviços } \\
\text { desenvolvidos pela } \\
\text { empresa. }\end{array}$ & $\begin{array}{l}\text { Facilitar a busca e uso } \\
\text { do conhecimento } \\
\text { identificado, levantado } \\
\text { e registrado pelos } \\
\text { colaboradores da } \\
\text { organização. }\end{array}$ & $\begin{array}{l}\text { Identificar estrutura para associação dos } \\
\text { conhecimentos explícitos relacionados aos } \\
\text { serviços de engenharia desenvolvidos e das } \\
\text { publicações relativas às áreas de atuação. } \\
\text { Classificar os conhecimentos de acordo com os } \\
\text { tipos de serviços executados e conforme as áreas } \\
\text { de atuação levantadas durante o planejamento } \\
\text { estratégico. }\end{array}$ \\
\hline
\end{tabular}

Quadro 8: Gestão do conhecimento em uma empresa de engenharia 


\begin{tabular}{|c|c|c|}
\hline AÇÕES & OBJETIVOS & ATIVIDADES \\
\hline $\begin{array}{l}\text { Estruturação de um } \\
\text { sistema para guarda, } \\
\text { recuperação, } \\
\text { atualização e difusão. }\end{array}$ & $\begin{array}{l}\text { Desenvolver ferramenta } \\
\text { de TI para disseminação } \\
\text { de informações e } \\
\text { conhecimentos explícitos } \\
\text { que permitem a } \\
\text { integração e o contato } \\
\text { entre os colaboradores. }\end{array}$ & $\begin{array}{l}\text { Analisar e implementar infra-estrutura } \\
\text { tecnológica de suporte para implantação da } \\
\text { estrutura analítica do conhecimento definida. } \\
\text { Definir objetivo do sistema focado na difusão do } \\
\text { conhecimento. } \\
\text { Pesquisar quais conhecimentos explícitos devem } \\
\text { ser disponibilizados pelo sistema. Estudar os } \\
\text { sistemas existentes na empresa, para evitar a } \\
\text { duplicidade e permitir a integração entre eles. } \\
\text { Planejar as etapas a serem desenvolvidas ao } \\
\text { longo da criação do aplicativo. }\end{array}$ \\
\hline $\begin{array}{l}\text { Definição de uma } \\
\text { estrutura de } \\
\text { levantamento e } \\
\text { registro do } \\
\text { conhecimento prático } \\
\text { (tácito). }\end{array}$ & $\begin{array}{l}\text { Levantar e criar, junto } \\
\text { com os colaboradores, } \\
\text { modelo para registro de } \\
\text { conhecimento prático } \\
\text { que possa auxiliar o } \\
\text { mapeamento dos } \\
\text { profissionais e a } \\
\text { disseminação para as } \\
\text { diversas áreas da } \\
\text { organização. }\end{array}$ & $\begin{array}{l}\text { Identificar colaboradores que detêm o } \\
\text { conhecimento prático dos serviços executados na } \\
\text { empresa. } \\
\text { Realizar entrevistas para levantamento de } \\
\text { questões relativas aos serviços escolhidos para o } \\
\text { protótipo. } \\
\text { Definir uma metodologia que possibilite a } \\
\text { melhoria contínua dos resultados, com o registro } \\
\text { de dicas para lidar com interferências e variáveis } \\
\text { que afetam o desempenho do trabalho. } \\
\text { Levantar as perguntas mais freqüentes sobre os } \\
\text { serviços estudados e listar os pontos críticos dos } \\
\text { processos. }\end{array}$ \\
\hline $\begin{array}{l}\text { Estudo de um sistema } \\
\text { de colaboração que } \\
\text { possa permitir uma } \\
\text { integração completa } \\
\text { entre as empresas } \\
\text { participantes dos } \\
\text { projetos. }\end{array}$ & $\begin{array}{l}\text { Integrar e colocar em } \\
\text { contato os colaboradores } \\
\text { que trabalham em } \\
\text { diferentes empresas e } \\
\text { atuam nos mesmos } \\
\text { projetos. }\end{array}$ & $\begin{array}{l}\text { Identificar meios para integrar empresas que } \\
\text { façam parte do mesmo projeto. } \\
\text { Pesquisar ferramentas de colaboração e estudar } \\
\text { suas características e pontos de atenção na sua } \\
\text { implantação e utilização. Analisar tecnicamente } \\
\text { os aplicativos para a escolha do sistema mais } \\
\text { adequado. } \\
\text { Adequar o uso da ferramenta de colaboração } \\
\text { com os sistemas e aplicativos já implantados na } \\
\text { empresa. } \\
\text { Desenvolver e utilizar sistema de colaboração } \\
\text { que possibilite a integração e compartilhamento } \\
\text { do conhecimento desenvolvido durante os } \\
\text { projetos com as empresas participantes. }\end{array}$ \\
\hline $\begin{array}{l}\text { Criação de uma } \\
\text { política de incentivo ao } \\
\text { registro e disseminação } \\
\text { do conhecimento. }\end{array}$ & $\begin{array}{l}\text { Utilizar o processo de } \\
\text { disseminação do } \\
\text { conhecimento, para que } \\
\text { os colaboradores possam } \\
\text { se sentir motivados e } \\
\text { incentivados para o } \\
\text { desenvolvimento do } \\
\text { conhecimento. }\end{array}$ & $\begin{array}{l}\text { Estudar as questões motivacionais junto aos } \\
\text { colaboradores da empresa. } \\
\text { Criar e realizar eventos presenciais que } \\
\text { incentivem a participação dos colaboradores e } \\
\text { permitam uma maior integração entre eles, bem } \\
\text { como possibilitar o mapeamento de } \\
\text { profissionais. } \\
\text { Elaborar uma estratégia de incentivo para que } \\
\text { haja envolvimento das equipes e profissionais } \\
\text { que dominam o conhecimento. } \\
\text { Definir um prêmio voltado para o incentivo ao } \\
\text { registro e disseminação do conhecimento. }\end{array}$ \\
\hline
\end{tabular}

\section{Quadro 8: Gestão do conhecimento em uma empresa de engenharia} (continuação) 
Quando um projeto conta com um planejamento e coordenação adequados ligado a um eficiente sistema de informação, evitam-se falhas durante a execução da obra, as atividades transcorrem de acordo com o previsto e os custos diminuem. $\mathrm{O}$ registro e a classificação das informações relevantes passam a constituir uma memória técnica, à qual a empresa sempre recorrerá para auxiliá-la no futuro.

Os sistemas de informação são uma importante ferramenta auxiliar ao processo de gestão do conhecimento (geração, codificação e compartilhamento) nos projetos de edificações e nas suas atividades de coordenação.

\subsection{Conhecimento e sistemas de informação}

É indispensável uma perfeita transmissão sistematizada das informações que subsidiam o desenvolvimento dos projetos de edificações. Várias pesquisas indicam que falhas de informação e defeitos na comunicação nas organizações podem ocasionar erros durante o processo produtivo, ou até mesmo, causar o insucesso de um empreendimento.

Como as informações estão distribuídas entre os diversos agentes do processo de projeto com enfoques diferentes e um grau de complexidade variado é importante a definição do conteúdo das informações, para a sua transmissão adequada e em tempo real. Para o sucesso de um projeto é vital que as informações sejam difundidas, de forma eficaz, a todos os seus colaboradores. Portanto, o estudo dos sistemas de informação tem uma importância fundamental.

A tecnologia da informação (TI) ajuda a captação, a difusão e o armazenamento do conhecimento organizacional associado ao conhecimento tácito, tratando as informações, desde a sua aquisição até a sua transmissão. A utilização da TI dentro dos sistemas de informação, com o auxílio dos recursos de informática, promove mudanças no processo de projeto, na sua coordenação, permitindo novas formas de comunicação.

Os sistemas de informação são um conjunto de componentes inter-relacionados para coletar, recuperar, processar, armazenar e distribuir a informação com o objetivo de facilitar o planejamento, o controle, a coordenação, a análise e o processo decisório dentro da organização (LAUDON; LAUDON, 1999).

A utilização de tecnologias apropriadas em conjunto com práticas efetivas, envolvendo a capacidade de criar e analisar práticas já existentes, permite que os profissionais tirem o melhor proveito de seus conhecimentos. $\mathrm{O}$ processamento de informações ocorre ao nível das várias redes informais ou de relacionamento, onde o conhecimento e o expertise (perito em sua área de conhecimento) estão dispersos e freqüentemente guardados em indivíduos e grupos. Esses grupos ao interagirem com ambientes eletrônicos adequados contribuem para o aprendizado organizacional e incrementam processos de inovação. (MACEDO, 2004)

“O conhecimento está no topo da escala que começa com os dados, passando a informação e o conhecimento, evoluindo em função do valor agregado". Dentro desta evolução também podem ser inseridos o saber e a competência, numa ordem ascendente. (FRANCO, 2001)

A formação do conhecimento organizacional se origina da transformação de dados, através de recursos de hardware e software, em informação que devidamente 
tratada pode gerar conhecimento. A informação só se transforma em conhecimento se incorporada às práticas individuais e organizacionais, o que exige uma mudança nos modelos individuais e coletivos dentro da empresa.

Segundo DAVENPORT; PRUSAK (1998), nas organizações o conhecimento está presente não apenas em documentos mas também em rotinas, processos e práticas e a transformação da informação em conhecimento é possível a partir de:

\section{- Comparação}

Como as informações relativas a um determinado assunto podem ter alguma aplicação em outras situações.

\section{- Conseqüências}

Implicação que uma informação pode ocasionar para a tomada de alguma decisão ou ação.

- Conexões

Relação entre o conhecimento adquirido e aquele já existente.

\section{- Conversação}

O que os profissionais pensam sobre determinada informação.

"Bases de conhecimento e sua gestão compreendem aspectos muito mais complexos do que bases de dados ou informações, porque devem ser capazes de armazenar não apenas idéias, mas os elementos contextuais como suas interrelações, história, uso passado. $\mathrm{O}$ conhecimento requer contexto e entendimento para ser aplicado apropriadamente." (RUGGLES apud MACEDO, 2004)

O processo de tratamento da informação na gestão do conhecimento compreende três dimensões (FRANCO, 2001):

- Coleta - os vários processos realizados nessa dimensão como: aquisição de dados, classificação, estocagem, recuperação, edição, verificação, apresentação, agregação, disseminação e avaliação.

- Análise - a dimensão mais crítica em um sistema de gestão de conhecimento. Consiste da análise propriamente dita:

- filtragem da informação;

- síntese: elaboração de um mapa de informação;

- hipótese: elaboração de cenários e construção;

- prova das suposições que guiam a síntese e a hipótese.

- Implicações - as possíveis respostas ao comportamento dos concorrentes ou mudanças no ambiente externo. Esta dimensão define como enfrentar as oportunidades e as ameaças e deve ser compartilhada entre o pessoal da gestão do conhecimento e os clientes.

A função de um sistema de informação deve ser a de "suprir os diversos níveis hierárquicos da empresa, ora transmitindo a informação compatível para a tomada de decisão, ora trazendo os resultados apontados, retroalimentando todo o processo gerencial" CINTRA; AMORIM (1998). Esses resultados serão satisfatórios, 
caso exista um planejamento e controle adequados de todas as atividades que constituem o processo.

A informação só tem qualidade para a empresa quando atende aos seguintes requisitos, de acordo com LIMA JR. apud CINTRA (1998):

- ser comparável, de modo que se possa comparar o planejado com o realizado;

- ser gerada em tempo hábil;

- ser confiável, pois as distorções são mais prejudiciais do que a falta de informações;

- possuir um nível de detalhamento compatível com as peculiaridades do setor a que deva atender.

Os níveis hierárquicos em uma organização e a correspondente necessidade de informação de cada um deles, segundo CINTRA (1998) são:

\section{- Estratégico}

Informações sumarizadas fornecidas pelos gerentes em nível comparativo: relações, índices.

\section{- Tático}

Informações mais detalhadas coletadas do operacional e gerando informações resumidas de subprojetos. Tem caráter não rotineiro e destina-se à tomada de decisões. Quanto maior o nível do tomador de decisão, maior a necessidade de informações não estruturadas.

\section{- Operacional}

Grande quantidade de informações necessárias para definir os serviços a serem executados. Trata da medição em nível individualizado sobre produto, processo e serviço. Cuida para que determinadas atividades continuem acontecendo dentro do ciclo operacional da empresa. Este nível trata das informações necessárias para a execução de uma determinada tarefa e, portanto, faz parte da rotina da organização.

"Bases de conhecimento e sua gestão compreendem aspectos muito mais complexos do que bases de dados ou informações, porque devem ser capazes de armazenar não apenas idéias, mas os elementos contextuais como suas interrelações, história, uso passado. O conhecimento requer contexto e entendimento para ser aplicado apropriadamente." (RUGGLES apud MACEDO, 2004)

O gráfico da figura 5 posiciona esses três níveis hierárquicos dentro de uma organização: estratégico $(\mathrm{E})$, tático $(\mathrm{T})$ e operacional $(\mathrm{O})$. 


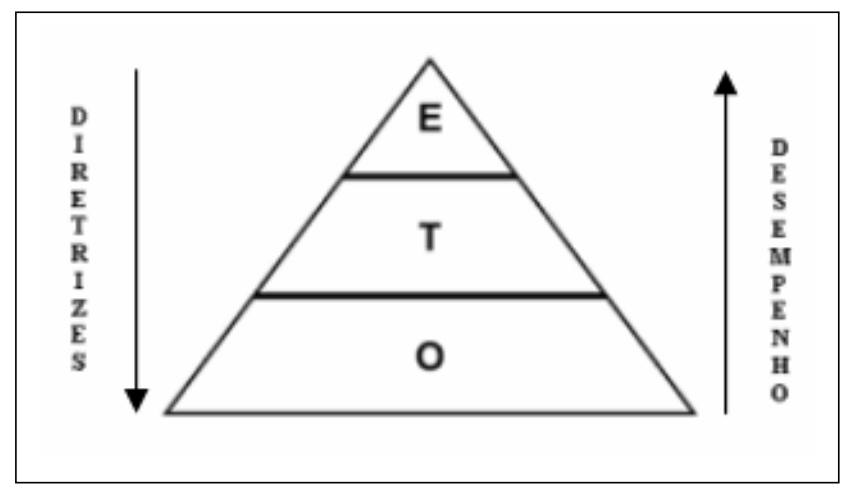

Figura 5: Pirâmide hierárquica

As informações que tramitam de cima para baixo através dos níveis hierárquicos constituem diretrizes. O retorno dessas informações retroalimenta o sistema de informação, indicando o desempenho de uma determinada atividade. Em relação ao processo decisório, quanto maior o nível hierárquico, mais sintetizadas e trabalhadas são as informações e maior é a responsabilidade ou o risco na tomada de decisões.

O sistema de informação de uma empresa exerce influência na implantação de medidas de racionalização, as quais têm por objetivo: minimizar os custos, maximizar os lucros, aumentar a produtividade e tornar a empresa mais competitiva. É importante salientar, que o sistema de informação utilizado pela empresa deve ser aberto. Desta forma, ele permitirá alterações quando necessário, garantindo a permanente eficácia do sistema de informações adotado.

A utilização adequada dos sistemas de informação aliado às tecnologias de informática permite distribuir, compartilhar e transferir, instantaneamente, informações, conhecimentos e experiências registradas (know-how), e gerar, desse modo, novos métodos e procedimentos que agreguem valor ao processo de projeto.

Desta forma, torna-se vantajoso para as empresas do setor de construção implantar um sistema de informação para auxiliar a gestão do conhecimento em sua estrutura organizacional.

A empresa objeto do estudo de caso demonstra a sua identificação com os conceitos práticos da gestão do conhecimento, aplicando-os para o cumprimento de suas estratégias e tornando-a, assim, altamente competitiva.

\section{GESTÃO DO CONHECIMENTO EM UMA CONSTRUTORA}

O estudo de caso foi realizado numa grande incorporadora e construtora sediada na cidade de São Paulo, com mais de trinta anos no mercado e que atua no Brasil, Uruguai e Oriente Médio.

A pesquisa empregada foi do tipo exploratória e descritiva-qualitativa. As informações foram obtidas através de questionários e entrevistas técnicas realizadas com uma das coordenadoras de projetos, com a controller, responsável pela área de desenvolvimento de projetos e com o executivo responsável pela gestão do conhecimento. 
Esta empresa apropriou-se da sua experiência para formalizar a gestão do conhecimento dentro da sua organização. O conhecimento, que no passado era um importante insumo para atingir seus objetivos estratégicos, passa a ser atualmente uma estratégia fundamental.

Sucessivas reorganizações influenciaram o desenvolvimento gradual da gestão do conhecimento na empresa, cronologicamente divido em três fases.

O quadro 9 descreve os marcos de cada uma dessas fases:

\begin{tabular}{|c|c|c|}
\hline Marco & Descrição & Fase \\
\hline 1 o & Torna-se produtora do conhecimento, deliberadamente. & \multirow{2}{*}{$\begin{array}{l}\text { Programa de } \\
\text { Produtividade } \\
\quad \text { Global }\end{array}$} \\
\hline 2o & $\begin{array}{l}\text { Passa a ser, também, educadora e formadora de competências } \\
\text { individuais. }\end{array}$ & \\
\hline 3o & $\begin{array}{l}\text { Constitui-se em produtora de conhecimento na concepção do } \\
\text { produto. }\end{array}$ & \multirow{4}{*}{$\begin{array}{l}\text { Sistema } \\
\text { próprio de } \\
\text { Construção }\end{array}$} \\
\hline $4 \mathrm{o}$ & Descobre a importância da contribuição de parcerias. & \\
\hline 5o & $\begin{array}{l}\text { Resolve a questão da competência organizacional nas suas } \\
\text { unidades. }\end{array}$ & \\
\hline 6o & $\begin{array}{l}\text { Soluciona a área da gestão do conhecimento sob todos os } \\
\text { aspectos, enquanto meio estratégico para atingir seus objetivos } \\
\text { empresariais, apropriando-se do capital intelectual que } \\
\text { adquiriu, produziu e desenvolveu. }\end{array}$ & \\
\hline 7o & $\begin{array}{l}\text { Redefine a sua competência essencial e passa a direcionar todo } \\
\text { o seu sistema de gestão nesse sentido. }\end{array}$ & \multirow{2}{*}{$\begin{array}{l}\text { Novo processo de } \\
\text { desenvolvimento } \\
\text { organizacional }\end{array}$} \\
\hline 8o & $\begin{array}{l}\text { Utiliza o conhecimento como estratégia para cumprir as suas } \\
\text { finalidades organizacionais. }\end{array}$ & \\
\hline
\end{tabular}

Fonte: baseado em SILVA (2005)

\section{Quadro 9: Marcos da gestão do conhecimento}

A partir de 1985, a empresa começou a se envolver, de uma forma mais efetiva, com as práticas de gestão do conhecimento para se adaptar às demandas do ambiente competitivo. As três fases cronológicas do desenvolvimento organizacional são abordadas sucintamente, a seguir:

\section{- Programa de Produtividade Global}

Esta primeira fase compreende o período entre 1985 e 1990. Os instrumentos de gestão do conhecimento, adotados pela empresa, foram: fóruns de engenharia para troca de experiências e documentação, vídeo-jornal e registro dos "inventos". A implantação desse novo programa repercutiu nas seguintes áreas da empresa:

\section{- Gestão Estratégica}

Explicitação dos princípios e das políticas, introdução do estilo participativo de administração, além da introdução e utilização de conceitos de engenharia de produção.

- Gestão da Produção 
Projeto ordem de produção, sistema integrado de gestão de obras (orçamento, planejamento e controles físico-financeiros) e projeto fábrica (movimentação, armazenagem de materiais e instalação do canteiro).

- Tecnologia

Racionalização dos processos e métodos preservando tecnologias convencionais, projeto de alvenaria e projeto central de estruturas.

- Recursos Humanos

Treinamento e desenvolvimento da mão-de-obra própria, treinamento gerencial em administração participativa e curso de racionalização do trabalho.

A estratégia da gestão do conhecimento nesta fase, baseou-se na transformação dos conhecimentos acadêmico e prático das equipes em conhecimento explícito para a sua utilização pelos diversos profissionais da empresa. Para o desenvolvimento da competência das equipes, foram resolvidas duas questões essenciais: como armazenar o conhecimento e como disseminá-lo, transformando-o em competência organizacional. A empresa recorre ao uso de equipes multidisciplinares e formais, que se sobrepõem à sua estrutura hierárquica e contrata equipes temporárias, com grande autonomia para desenvolver projetos inovadores.

\section{- Sistema Próprio de Construção}

Esta fase de 1990 a 1998, foi influenciada pelo cenário externo de uma economia competitiva: a descoberta de novas tecnologias; a necessidade de influenciar os profissionais de projeto e os clientes para adesão às novas tecnologias; o uso da microinformática fazendo parte da cultura; a consagração do estilo participativo no mundo empresarial e a formação de alianças, parcerias e redes competitivas entre as empresas. Assim, o foco da estratégia da gestão do conhecimento na empresa consistiu em:

- atuar na concepção do produto e na venda ao investidor e ao usuário final;

- constituir unidades e empresas especializadas na aplicação dos novos conhecimentos, abreviando a curva do aprendizado e garantindo a competência organizacional;

- desenvolver antigos e novos fornecedores.

Para atingir essa estratégia foram realizadas as seguintes ações:

- Atuação na concepção do produto - engenharia e análise do valor.

- Desenvolvimentos profissionais e planos de carreira.

- Curso de engenharia de produção para a construção civil.

- Parcerias com fornecedores para novas soluções.

- Introdução de novos conceitos de construção.

- Intercâmbios e seminários.

- Aquisição e importação de novas tecnologias.

- Unidades de negócio e empreendimentos conjuntos (joint ventures). 
Os novos instrumentos da gestão do conhecimento utilizados foram os seguintes:

- Propostas técnicas - onde o conhecimento tácito torna-se explícito como "subproduto" do trabalho e com um discurso próprio de venda externa e "interna".

- Informática em rede e bancos de dados corporativos integrados para a gestão de empreendimentos.

- Acervo técnico (embrião de um portal corporativo) e biblioteca.

- Boletim periódico: reconhecimento para os colaboradores internos; explicitação e documentação do conhecimento produzido e limitações: coleta, detalhamento e timing (cronograma).

- Convenções de obras.

- Sistema de Gestão da Qualidade:

- ferramenta gerencial no molde das normas da série ISO 9000, com procedimentos e normas disponibilizados na intranet;

- transformar competência individual e das equipes de trabalho em competência organizacional através da sua fixação nos sistemas de gestão sem torná-los rígidos ou herméticos;

- avaliação - requer grande adaptabilidade e flexibilidade em empresas orientadas por projetos;

· solução - trabalhar dentro do conceito de "repertório renovável".

Até então, a estratégia da empresa baseia-se na satisfação dos clientes (medida pela conformidade de seus produtos), diferenciais competitivos, acumulação e disponibilização do conhecimento, informática, foco em processos e em tecnologia de construção e terceirização.

\section{- Novo Processo de Desenvolvimento Organizacional}

Nesta fase, a partir de 1999, a nova estratégia empresarial foi impulsionada pela globalização, pelos conceitos de empresa inteligente (empresa brain) e diferenciada, pela criação de valor para o cliente, informação, força da marca, foco em sistemas e em segmentos de clientes e gestão sobre a cadeia de valor (strategic sourcing).

A empresa iniciou um novo processo de desenvolvimento organizacional para "refundar" a empresa, reformulando as bases de sua identidade, redefinindo o seu posicionamento estratégico e redesenhando a sua estrutura e os seus processos. Isto através da revisão da sua missão e visão empresarial, afirmação dos seus valores éticos e sistematização do seu planejamento estratégico.

A missão e os valores da empresa são divulgados de forma consistente. A sua macro-estratégia é comunicada para todos os níveis organizacionais. Esta fase objetiva alcançar as seguintes estratégias:

- Possuir uma marca forte, associada a produtos diferenciados e de alta qualidade. 
- Segmentar o mercado e desenvolver competências específicas aos respectivos segmentos.

- Criar e consolidar uma "cultura de intimidade" com o cliente.

- Vender conhecimento, expandindo a atuação da empresa na cadeia de valor, além da atividade de construção.

A política institucional de qualidade da empresa estabelece mecanismos permanentes para a sustentação da qualidade, que levam em conta a qualificação profissional e a aprendizagem organizacional, que consiste em desenvolver "sistemas que aprendem" baseados no conhecimento dos profissionais da empresa. Determina que a empresa, para o aumento do seu capital intelectual, deve manter canais apropriados para: a captação, o armazenamento, a disponibilização e a aplicação de todo o conhecimento gerado e compartilhado que reverta em benefício do aprimoramento contínuo da eficácia empresarial.

Através dos novos instrumentos de gestão do conhecimento instituídos pela empresa, os sistemas de gestão de projetos e de competências integradas, caracterizou-se o $8^{\circ}$ marco da gestão do conhecimento. A missão da empresa é ser agente de mudança e progresso da engenharia, unindo e mobilizando talentos e competências da cadeia de valor.

Os principais procedimentos da gestão do conhecimento relativos ao processo de projeto e à sua coordenação estão compilados num sistema de gestão de projetos, que contém metodologias para a captura das lições aprendidas e posterior discussão em reuniões gerenciais periódicas.

\subsection{Gestão de Projetos de Edificações}

O sistema de Gestão de Projetos implantado pela construtora estudada baseia-se na metodologia do PMI (Project Management Institute). Esse modelo padrão é explicitado por meio de processos de gerenciamento de projetos organizados em nove áreas do conhecimento: Integração, Escopo, Tempo, Custo, Qualidade, Recursos Humanos, Comunicações, Riscos e Aquisições.

A atuação conjunta dos grupos de processos é necessária em qualquer projeto. Eles possuem "claras dependências internas e devem ser realizados na mesma seqüência em cada projeto, independentemente da área de aplicação ou das especificações do ciclo de vida do projeto aplicado". (PMI, 2004)

Os cinco grupos de processos de gerenciamento de projetos (iniciação, planejamento, execução, monitoramento-controle e encerramento), não devem ser confundidos com as fases do projeto. O sistema cobre todo o ciclo de vida do empreendimento desde o seu início até a sua pós-execução. Ele é “um conjunto de fases do projeto, geralmente em ordem seqüencial, cujos nomes e quantidades são determinados pelas necessidades de controle da organização ou organizações envolvidas no projeto". PMI (2004)

A metodologia do PMI adotada pela construtora visa ampliar o conhecimento, assim como, desenvolver as competências dos profissionais da área. $\mathrm{O}$ gerenciamento de projetos constitui-se na aplicação de conhecimentos, habilidades, ferramentas e um conjunto de atividades técnicas, voltadas à implantação de 
empreendimentos, coordenando e otimizando os diferentes recursos, a fim de atender aos seus objetivos.

A incorporadora dedica-se, em seus empreendimentos imobiliários, à construção de edifícios residenciais, comerciais, industriais, de hospitais, hotéis, escolas, centros de lazer, de cultura e de educação. A competência essencial (core competence) da empresa consiste na gestão de projetos complexos de desenvolvimento imobiliário, compreendendo os conceitos de EPC (engineering, procurement e construction) e a construção rápida (fast construction). No projeto integrado EPC, a construtora é responsável, desde a planta até a unidade pronta, pelos serviços de engenharia, fornecimento de equipamentos e materiais, construção civil e montagem.

Na realização de seus empreendimentos imobiliários, a construtora prioriza a coordenação de projetos. A empresa possui sistema de gestão da qualidade certificado e sistemas de qualidade específicos para o escopo de fôrmas, escoramentos e equipamentos para estruturas de concreto.

Em sua concepção, na atividade de coordenação residem as maiores oportunidades de redução de custos desnecessários, "retrabalhos e defeitos crônicos" das edificações. Muitas vezes, mesmo que não faça parte de seu escopo contratual, a empresa antecipa-se na coordenação e realiza, também, a compatibilização por espontânea vontade, ciente dos ganhos que isso lhe trará.

Quando a construtora entra no empreendimento imobiliário desde o início, ela coordena todo o ciclo de vida desde a viabilização prévia, a concepção do projeto, a fase de orçamento passando pelo desenvolvimento e detalhamento de projetos, especificações, execução até a entrega final. A atividade de coordenação de projeto é tarefa interna da empresa que designa uma equipe própria para assumir essa responsabilidade, onde cada obra tem o seu coordenador de projetos, geralmente, arquiteto.

Mas algumas vezes, a construtora atua como simples executora de projetos prontos, sem a possibilidade de alterações. Neste caso, o trabalho de coordenação do processo de projeto se inicia junto com a mobilização da obra e a sua equipe coordena e supervisiona toda a execução.

O coordenador de projetos acompanha a obra e é responsável pela emissão da documentação e pela elaboração dos manuais, para entrega aos usuários. As suas principais atribuições são:

- cobrar respeito aos prazos estipulados;

- garantir que todas as interferências estejam resolvidas;

- obter dos projetistas e fornecedores as melhores soluções de projeto, ou seja, a melhor relação entre custos e benefícios;

- zelar pelo comprometimento e a motivação da equipe.

Os procedimentos e as rotinas adotados na coordenação são disponibilizados via intranet da própria empresa, e dão ênfase à supervisão e ao recebimento de etapas da obra. Existe em alguns projetos um gerenciamento do fluxo de arquivos eletrônicos e documentos de projeto, incluindo padrões para troca de arquivos eletrônicos entre todos os parceiros envolvidos. A empresa adota um sistema 
integrado de arquivos informatizados que consiste em bancos de dados corporativos integrados para a gestão dos empreendimentos imobiliários e outros sistemas desenvolvidos sob medida para as demais aplicações.

Diversos recursos de informática apóiam a coordenação no processo de projeto. $\mathrm{O}$ desenho auxiliado por computador em ambiente CAD é utilizado para a compatibilização nas diversas fases de projeto. A coordenação tem a incumbência de compatibilizar os vários projetos, através de diversos layers do AUTOCAD, de plantas plotadas, etc. Às vezes, porém, esse trabalho é terceirizado.

As reuniões de coordenação de projetos, registradas em atas, são, geralmente, presenciais. São transmitidos, outrossim, dados e informações através de correio eletrônico. Os profissionais que participam das reuniões de coordenação são arquitetos, engenheiros, técnicos e o pessoal da área de engenharia. O engenheiro da obra só participa quando já está designado. Dependendo da fase do processo de projeto, podem ocorrer duas reuniões por semana. São marcadas reuniões específicas para validar os diversos projetos. Eles são avaliados e validados pelo gerente de projeto e ou pela área de engenharia.

A construtora realiza reuniões de coordenação de projetos com fornecedores de materiais de construção para analisar a viabilidade do projeto a executar. Os fornecedores em sua capacidade de contribuir com soluções são convidados a colaborar com conhecimento tecnológico. Para viabilizar e formalizar parcerias a construtora procede, regularmente, à avaliação de seus fornecedores.

Para estudar melhorias a serem implantadas em cada novo projeto a ser desenvolvido, é criado um fórum de discussões com a participação de diversos profissionais. Ocorrem, paralelamente, conversas informais com os diversos projetistas para avaliar, antecipadamente, o projeto. A construtora possui, em seu quadro, uma considerável equipe de arquitetos. Os demais profissionais de projeto são terceirizados para cada etapa do empreendimento. A empresa realiza, também, a avaliação de projetistas para viabilizar parcerias. Cerca de 12 empresas de projeto estão ligadas à construtora por um sistema próprio de competências integradas que reduz a distância entre os fornecedores, os profissionais de projeto e os que executam a obra.

O projeto a realizar é o principal vetor de intercâmbio de conhecimento, concretizado através do sistema de competências integradas, onde existe a oportunidade dos agentes envolvidos terem a oportunidade de agregar valor, desde as etapas de viabilização e concepção do produto-edifício.

O sistema de competências, baseado em propósitos, valores e princípios éticos próprios, conta com um mecanismo de interação dos diversos segmentos da cadeia produtiva que compõe a indústria da construção para conceber e viabilizar as melhores soluções. É um esforço conjunto de integração dos vários parceiros de um empreendimento imobiliário na busca das melhores soluções tecnológicas, de funcionalidade e segurança para o usuário final, além de conforto, estética e qualidade de vida.

O sistema de competências da construtora engloba um grupo aberto e em crescimento de profissionais de projeto, consultores, profissionais que executam a obra, fornecedores, clientes e outros colaboradores, além de seus parceiros 
estratégicos e investidores. A contribuição da TI para a integração dessas diversas competências se materializa através de um portal colaborativo específico.

A empresa tem uma expressiva carteira de "clientes leais" e parceiros em diversos negócios. Ela admite aprender com os seus clientes e realizar alianças, freqüentemente, relacionadas a decisões estratégicas da empresa. $O$ trabalho de integração entre as suas equipes visa produzir as soluções mais adequadas para os diferentes clientes de cada empreendimento. Somando competências e a experiência de cada um de seus participantes, o sistema de competências da empresa procura conciliar a melhor solução, em termos técnicos, estéticos e funcionais, para materializar o projeto de edificações.

A construtora realiza os seguintes projetos do produto e para produção: arquitetura, paisagismo, fundações, elétrica, hidráulica, automação, ar condicionado, impermeabilização, caixilharia e fachadas. Ela mantém procedimentos de controle de recebimento, análise crítica e verificação, ao final de cada etapa de projeto e utiliza controle de revisões e alterações.

Os projetos de engenharia complementares ao projeto de arquitetura são terceirizados. Os profissionais de projeto externos nem sempre são contratados pela construtora. Muitas vezes entram no empreendimento pelas mãos de arquitetos e investidores, o que resulta, em alguns casos, em pouco entrosamento entre os diversos intervenientes da obra. Entretanto, o sistema de competências da construtora busca alcançar o melhor, resultado, com um espírito de trabalho em equipe.

Há empreendimentos onde o cliente define o autor do projeto de arquitetura para, assim, atender às suas expectativas. A coordenação de projetos, neste caso, tem que se adequar a uma situação "delicada" (na concepção da empresa), diferente da usual. O sistema de competências tem a agilidade para atuar como facilitador da execução dos projetos de arquitetura e conta com profissionais de projeto, consultores e fornecedores, capazes de ajudar a transformar os projetos em realidade.

Em um processo de criação compartilhada, como o da coordenação de projetos, existem algumas divergências de opinião, as quais são naturais. Segundo a construtora, os diferentes graus de conhecimento e comprometimento dos envolvidos no processo de projeto, a inflexibilidade de alguns, as suas resistências a alterações ou modificações em seu trabalho são as principais dificuldades encontradas na atividade de coordenação de projetos.

Após o término da construção, a equipe de coordenação de projetos participa de reuniões onde são analisadas e discutidas com outras equipes, todas as etapas do empreendimento. Esta é uma preocupação interna da empresa, que visa, assim, obter uma excelência constante em seus empreendimentos.

Para desenvolver empreendimentos imobiliários com maior qualidade, a construtora investe na capacitação de seus profissionais da área técnica e promove uma postura diferenciada mais receptiva ao aprendizado, visando, assim, um fluxo do conhecimento eficiente e ágil entre todos os envolvidos no processo produtivo. Assim, os sistemas desenvolvidos são submetidos a métodos de fiscalização para a garantia da qualidade de acordo com padrões pré-definidos. 
A empresa pesquisada está focada na gestão do conhecimento para a realização de seus empreendimentos e projetos. Há alguns anos, vem redefinindo as suas bases organizacionais e o seu posicionamento estratégico, de forma a incutir a gestão do conhecimento na sua cultura organizacional, através, por exemplo, dos seus valores e missão. A gestão do conhecimento, no novo processo de desenvolvimento organizacional, constitui-se em uma macro-estratégia da empresa, com ênfase no desenvolvimento de competências e na reformulação dos seus processos internos, estruturados a partir do sistema de gestão de projetos.

O mundo empresarial pode ser dividido em três grandes grupos, as empresas que aprendem, as tradicionais e as empresas pequenas e atrasadas, de acordo com TERRA (1999). No presente estudo de caso, foi aplicado um questionário adaptado ao proposto por este pesquisador. Assim, confirmou-se pelas respostas obtidas, que a empresa estudada realmente adota práticas de gestão do conhecimento. Isto é, está inserida no grupo das empresas que aprendem, em geral, companhias líderes de mercado.

Portanto, a sua cultura organizacional demonstra-se focada no aprendizado contínuo e na inovação, ao sistematizar e estruturar a área de conhecimento da empresa. Assim, realiza-se uma efetiva gestão do conhecimento que, conforme TERRA (1999), deve monitorar e redirecionar, regularmente, o ambiente e os valores organizacionais, onde as estratégias empresariais e os investimentos em infra-estrutura promovem o desenvolvimento do conhecimento quando existe uma atmosfera propícia ao aprendizado, à colaboração e ao compartilhamento de conhecimentos explícitos e tácitos.

\section{CONCLUSÃO}

A gestão do conhecimento, de uma forma ou de outra, não deixa de estar implícita nos complexos empreendimentos imobiliários, visto que o conhecimento é fundamental na concepção do produto e no desenvolvimento do processo de projeto. Atualmente, as empresas de construção apresentam uma postura mais efetiva com relação a essa questão, visto que algumas já começam a adotar práticas específicas voltadas à gestão do conhecimento. Existe por parte das empresas do setor uma preocupação crescente com a gestão das informações e o processo de acúmulo do conhecimento dentro da sua estrutura organizacional.

Em um ambiente econômico e tecnologicamente competitivo, as empresas, com perfil atualizado, não podem prescindir da gestão do conhecimento visando à qualidade e agregando valor aos seus produtos. Esses conceitos contribuem para que os empreendimentos imobiliários brasileiros estejam em um padrão de qualidade e excelência de nível internacional.

No caso de uma empresa de engenharia ou construtora torna-se mais evidente a necessidade de gerir o conhecimento de diversas especialidades, em relação a aspectos técnicos e gerenciais, e desenvolver competências visando à máxima integração entre os intervenientes do processo de projeto. 


\section{REFERÊNCIAS BIBLIOGRÁFICAS}

BITTENCOURT, E. Gerenciamento do capital intelectual. Estado de Minas, Belo Horizonte, 20 jan. 2002.

CINTRA, M. A. H. Sistemas de informação e gerenciamento de projetos: um estudo de caso na cidade de Juiz de Fora. 1998. 209 f. Dissertação (Mestrado em Engenharia Civil) - Escola de Engenharia, Universidade Federal Fluminense, Niterói.

CINTRA, M. A. H.; AMORIM, S. R. L. Sistemas de informação no gerenciamento de projetos aplicação do DFD: diagrama de fluxo de dados. In: CONGRESSO DE ENGENHARIA CIVIL, 3., 1998, Juiz de Fora. Anais... Juiz de Fora: UFJF, 1998. 8 p.

DAVENPORT, T.; PRUSAK, L. Working knowledge: how organizations manage what they know. Boston: HBS Press, 1998.

FRANCO, E. M. Gestão do conhecimento na construção civil: uma aplicação dos mapas cognitivos na concepção ergonômica da tarefa de gerenciamento dos canteiros de obras. 2001. 252 f. Tese (Doutorado em Engenharia de Produção) - Centro Tecnológico, Universidade Federal de Santa Catarina, Florianópolis.

JOHANNESSEN, J.; OLSEN B.; OLAISEN, J. Aspects of innovation theory based on knowledge-management. International Journal of Information Management, 19, abr. 1999. p.121-139.http://dx.doi.org/10.1016/S0268-4012(99)00004-3

LAUDON, K. C.; LAUDON, J. P. Information system and the internet: a problem-solving approach. 4. ed. The Dryden Press Translation, 1999.

MACEDO, T. M. B. Redes informais nas organizações: a co-gestão do conhecimento. Disponível em: <http://www.portalsbgc.org.br/sbgc/portal/>. Acesso em: 03 ago. 2004.

MUSSI, C. C.; ANGELONI, M. T. Mapeamento do conhecimento organizacional: um suporte ao compartilhamento do conhecimento tácito. In: INTERNATIONAL SYMPOSIUM ON KNOWLEDGE MANAGEMENT, 2000, Curitiba. Anais... Curitiba: PUC-PR, 2000.

NEVES, R. M.; FORMOSO, C. T. Método para identificação de competência. In: SIMPÓSIO BRASILEIRO DE GESTÃO E ECONOMIA DA CONSTRUÇÃO, 3., 2003, São Carlos. Anais... São Carlos: UFSCar, 2003. CD-ROM.

NONAKA, I.; TAKEUCHI, H. Criação do conhecimento na empresa. Rio de Janeiro: Campos, 1997. 358 p.

OLIVEIRA JUNIOR, M. M. Competências essenciais e conhecimento na empresa. In: FLEURY, M. T. L.; OLIVEIRA JUNIOR, M. M. (Org.). Gestão estratégica do conhecimento: integrando aprendizagem, conhecimento e competências. São Paulo: Atlas, 2001. p. 121-156.

PEZZO, M. Sociedade da Informação. Revista Univerciência da UFSCar, São Carlos, ano 2, n..4, p. 4-10, maio 2003.

PROJECT MANAGEMENT INSTITUTE - PMI. A Guide to the Project Management Body of Knowledge (PMBOK® Guide). 3. ed. Newtown Square, Penn., USA: PMI, 2004. 388 p.

RUAS, R. Desenvolvimento de competências gerenciais e contribuição da aprendizagem organizacional. In: FLEURY, M. T. L.; OLIVEIRA JUNIOR, M. M. (Org.). Gestão estratégica do conhecimento: integrando aprendizagem, conhecimento e competências. São Paulo: Atlas, 2001. p. 242-269. 
SALIM, J. J. Gestão do conhecimento e transformação organizacional. Disponível em: <http://www.fgvsp.br/conhecimento/home.htm>. Acesso em: 30 jun. 2004.

SANTIAGO JÚNIOR, J. R. S. O desenvolvimento de uma metodologia para gestão do conhecimento em uma empresa de construção civil. 2002. 127 f. Dissertação (Mestrado em Engenharia de Produção) - Escola Politécnica, Universidade de São Paulo, São Paulo.

SILVA, M. V. M. F. P. As atividades de coordenação e a gestão do conhecimento nos projetos de edificações. 2005. 202 f. Dissertação (Mestrado em Construção Civil) - Centro de Ciências Exatas e de Tecnologia - Universidade Federal de São Carlos, São Carlos.

SILVA, M. A. C.; SOUZA, R. Gestão do processo de projeto de edificações. 1. ed. São Paulo: O Nome da Rosa, 2003. 181 p.

SOUZA E SILVA, M. F.; HEINECK, L. F. M. Equipes de projeto de edificações e seu potencial como equipes de gestão de conhecimento: uma reflexão preliminar. In: WORKSHOP NACIONAL: GESTÃO DO PROCESSO DE PROJETO NA CONSTRUÇÃO DE EDIFÍ́CIOS, 1., 2001, São Carlos. Anais... São Carlos: EESC/USP, 2001. CD-ROM.

SPENDER, J. C. Gerenciando sistemas de conhecimento. In: FLEURY, M. T. L.; OLIVEIRA JUNIOR, M. M. (Org.). Gestão estratégica do conhecimento: integrando aprendizagem, conhecimento e competências. São Paulo: Atlas, 2001. p. 27-49.

TERRA, J. C. C. Gestão do conhecimento: aspectos conceituais e estudo exploratório sobre as práticas de empresas brasileiras. 1999. 293 p. Tese (Doutorado em Engenharia de Produção) - Escola Politécnica, Universidade de São Paulo, São Paulo.

TRISKA, R. Proposta de uma base de dados institucional para a gestão do conhecimento. 2001. 119 f. Tese (Doutorado em Engenharia de Produção) Programa de Pós-graduação em Engenharia de Produção, Universidade Federal de Santa Catarina, Florianópolis.

YAMAUCHI, V. Implementação de inovação em projetos através da gestão do conhecimento. In: SIMPÓSIO BRASILEIRO DE GESTÃO E ECONOMIA DA CONSTRUÇÃO (SIBRAGEC), 3., 2003, São Carlos. Anais... São Carlos: UFSCar, 2003. CD-ROM. 